Continued from previous page

the activity level doubles in one year is just one of several urgent matters with which these folks have grappled in 1985 .

Under the direction of Julia Phillips, MRS has pomulgated its messages on meetings and other activities to a wider-than-ever audience. The Public Relations and Publicity Committee which Julia chaired in 1985 had been working a group in the previous year and by the end of 1985 had imposed an unprecedented degree of order and comprehensiveness to MRS publicity efforts. Much of the mechanical aspects of these tasks have been transferred to the MRS Headquarters.

The space occupied by MRS Headquarters increased by $50 \%$ in 1985 as the number on our staff doubled. This was in response to increasing activity in MRS as well as to the need to centralize tasks done previously by dispersed volunteers. Headquarters has accomplished a great deal under the direction of MRS Executive Director John Ballance and with the involvement of a staff committed to excellence.

Leading an organization growing at the pace MRS is experiencing has been an exciting and challenging job. That it was a possible job is a consequence of the MRS team effort and the dedication of the individuals involved. The I 985 Executive Committee of the Society included Secretary Rod Ewing, Treasurer Clif Draper, Second Vice President Kathy Taylor, First Vice President Gordon Pike, and Immediate Past President Woody White. The indefatigable involvement of these officers and Executive Director John Ballance, in all aspects of the Society's work not only made the job possible, but produced progress of which we can be proud. It was a dis tinct privilege and pleasure to work with these individuals whose continued service to MRS guarantees its future.

At the beginning of 1986 , it is of less value to review the past year than it is to look to the coming year and the new challenges it presents. MRS President Gordon Pike does that in this issue of the BULLETIN. MRS is a young and flexible organization and one with which it is rewarding to be associated. Every members' involvement is welcomed and encouraged for the coming year.

Milkis

\title{
1986 Fall Meeting Preview
}

\section{Chang, Janzten, Roberto Steer 1986 Boston Meeting}

Although the highly successful 1985 Fall Meeting is just barely over, the technical programming and facilities arrangements for the 1986 Meeting are now in progress and under the direction of Program Chairs R.P.H. Chang, C.M. Jantzen, and J.B. Roberto. They report that 22 individual symposia are planned for the meeting, representing the work of over 50 symposia chairs from the United States, Australia, Japan, and UK. Topics will span alloys, ceramics, polymers, graphite, and cement, as well as materials for specialized applications, fractals and solitons. The Meeting will also be augmented by the MRS Equipment Exhibit and an extensive short course program.

\section{Diverse Technical Interests, \\ Broad MRS Support}

The three meeting chairs bring a wealth of professional experience to the meeting. Bob Chang has served in a number of capacities for MRS, currently holding the positions of Chairman, International Relations and Councillor. Along with B. Abeles, he organized the Society's first symposium on Plasma Synthesis and Etching of Electronic Materials in 1984 and has also served on the Program, Awards, Long Range Planning, and Corporate Participation Committees. Chang has been with AT\&T Bell Laboratories since 1971 where he is currently actively working on electronic materials for integrated optoelectronic devices. He has over 170 publications (including patents) to his credit.

According to Chang, "The unique programming plus a strong emphasis on the

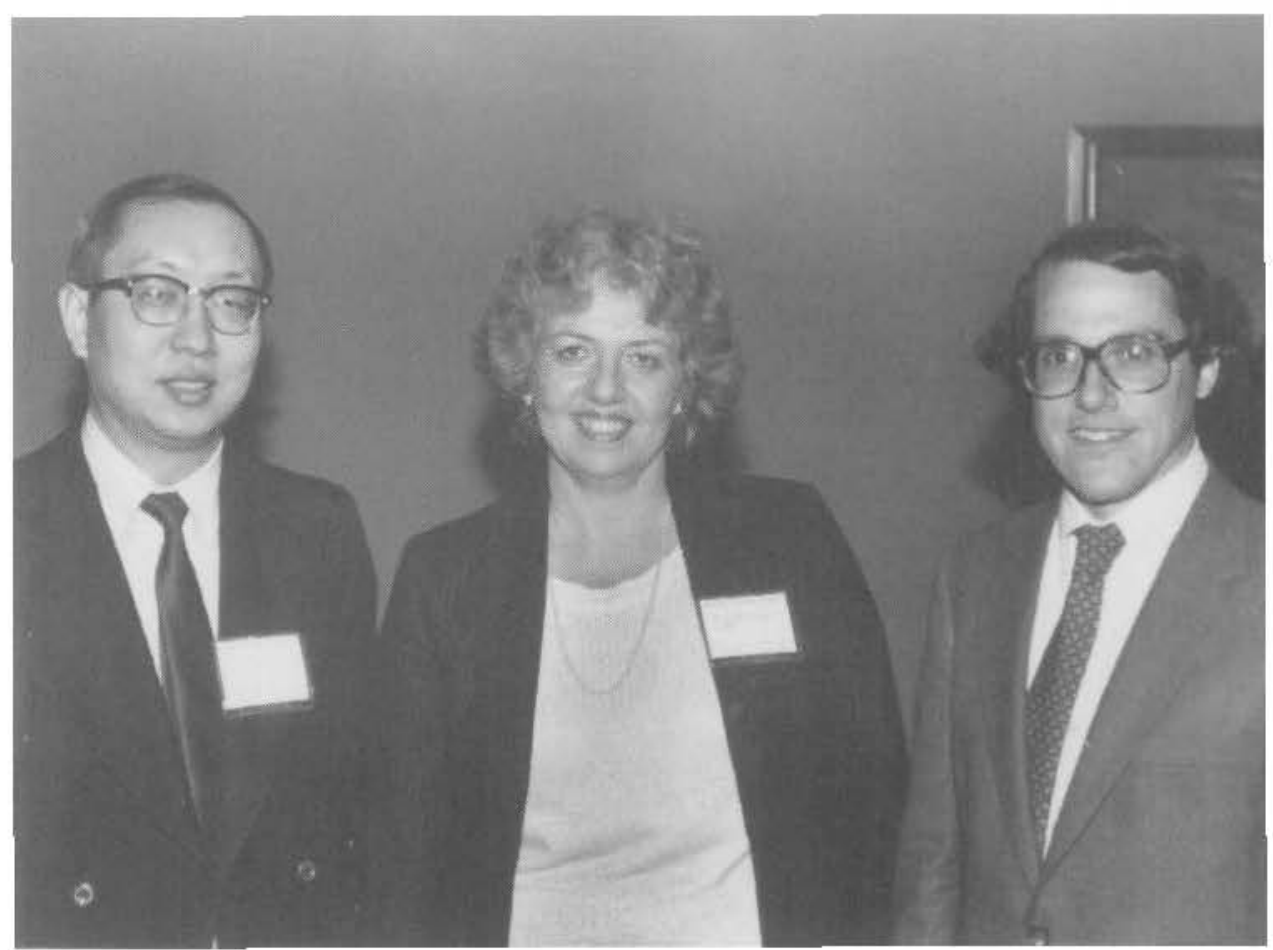

1986 Fall Meeting Chairs (left to right): Bob Chang, Carol Jantzen, and Jim Roberto.

science of materials and increased attendance by colleagues from abroad continues to make MRS Meetings of ever increasing importance. Our goal in Boston in 1986 is to help the symposia organizers continue to add to this tradition."

Carol Jantzen cochaired the Eighth Symposium on the Scientific Basis for Nuclear Waste Management with R.C. Ewing and
J.A. Stone at the 1984 MRS Fall Meeting, and continued her involvement with the symposium series at the Ninth Symposium held in Stockholm in September 1985. (The Tenth Symposium in the series will be held during the 1986 Fall Meeting.) Jantzen is staff chemist for DuPont's Savannah River Laboratory and is actively involved with Continued 
Continued from previous page

the Nuclear Division of the American Ceramic Society. She is the author of nearly 50 publications.

"A number of exciting events are planned for the Boston Meetings in 1986," she said. "Among the 22 symposia are a symposium on Hydration of Cement which will hold a joint session with the third symposium on Fly Ash and Coal Conversion By-Products and the Society's second symposium on Materials Processing in the Reduced Gravity Environment of Space will be held."

Jim Roberto has been with the Solid State Division of Oak Ridge National Laboratory since 1974, serving in various capacities including group leader and manager of ORNL's Plasma Materials lnteractions Program. He is currently on leave as technical assistant to ORNL's associate director for physical sciences. Roberto is the author of over 40 technical publications and has edited two books. He cochaired, with R.W. Carpenter and M.C. Wittels, the symposium on Advanced Photon and Particle Techniques for the characterization of Defects in Solids in the 1984 MRS Fall Meeting.

"I have yet to meet a materials-oriented scientist or engineer who was not enthusiastic about the format and content of MRS meetings," Robert said. "As program chairs, we intend to continue the tradition of high-quality symposia spanning fundamental and applied materials research in the 1986 Fall Meeting."

The goal of the three program chairs is to use the experiences gained from the 1984 and 1985 highly successful Fall Meetings to make the upcoming meeting the best ever. The meeting will again use video links from one meeting room to another and provide a centralized manuscript room to facilitate the manuscript review process toward rapid post-meeting publication of the 17 anticipated proceedings volumes. An improved meeting locator is under development to enable attendees to move easily between symposia for maximum benefit from the meeting.

The I 986 MRS Fall Meeting will be held December 1-6 at the Boston Marriott Hotel/Copley Place. Symposia to be held are:

- Symposium $A$ :

Beam-Solid Interactions and Transient Processes

- Symposinm B:

Photon, Beam and Plasma Stimulated Chemical Processes at Surfaces

- Symposium C:

Science and Technology of

Microfabrication

- Symposium D:

Interfaces, Superlattices and Thin Films

- Symposium E:

Advances in Stuctural Ceramics

- Symposium E:

Scattering, Deformation and Fracture in Polymers

- Symposium G:

Science and Technology of Rapidly

Quenched Alloys

- Symposium H:

High Temperature Ordered Intermetallic Alloys

- Symposium I:

Characterization of Defects in Solids

- Symposium ]:

Physical and Chemical Properties of Thin Metal Overlays and Alloy Surfaces
- Symposium K:

Intercalated Graphite

- Symposium L:

Scientific Basis for Nuclear Waste Management $X$

- Symposium $M$ :

Microstructural Development During Dehydration of Cements

- Symposium N:

Fly Ash and Coal Conversion By-

Products: Characterization, Utilization and Disposal III

- Symposium 0 :

Materials Processing in the Reduced

Gravity Environment of Space

- Symposium $P$ :

Optical Fiber Materials Properties

- Symposium Q:

Diluted Magnetic (Semimagnetic)

Semiconductors

- Symposium R:

Materials for Infrared Detectors and Sources

- Symposium S:

Superconducting Materials

- Symposium T:

Solitons in Materials Science

- Symposium U:

Fractal Aspects of Materials

- Symposium Vi

Multi-Component Ultra-Fine Structures

- Sympositum X:

Frontiers of Materials Research

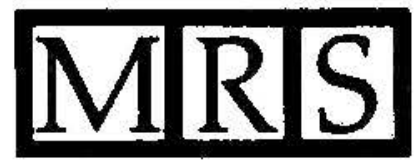

\section{MRS Corporate Participation Program}

As a Corporate Affiliate of the Materials Research Society, your organization is kept abreast of the Society's goals and activities and afforded special opportunities to enhance your research programs through:

- Subscription to MRS BULLETIN

- Advance notification of meeting programs and events

- Discounts on symposia proceedings

- Free employment ad placement in MRS BULLETIN

And more.

For complete details on the program, contact:

Julia Phillips, AT\&T Bell Laboratories, (201) 582-4428 or

MRS Headquarters, 9800 McKnight Road, Suite 327, Pittsburgh, PA 15237; (412) 367-3003 